\title{
Traumatic spinal cord injury: current concepts and treatment update
}

\author{
Traumatismo raquimedular: conceitos atuais e atualizações terapêuticas \\ Carolina Rouanet ${ }^{1}$, Danyelle Reges ${ }^{1}$, Eva Rocha1 , Vivian Gagliardi', Gisele Sampaio Silva
}

\begin{abstract}
Spinal cord injury (SCI) affects 1.3 million North Americans, with more than half occurring after trauma. In Brazil, few studies have evaluated the epidemiology of SCl with an estimated incidence of 16 to 26 per million per year. The final extent of the spinal cord damage results from primary and secondary mechanisms that start at the moment of the injury and go on for days, and even weeks, after the event. There is convincing evidence that hypotension contributes to secondary injury after acute SCI. Surgical decompression aims at relieving mechanical pressure on the microvascular circulation, therefore reducing hypoxia and ischemia. The role of methylprednisolone as a therapeutic option is still a matter of debate, however most guidelines do not recommend its regular use. Neuroprotective therapies aiming to reduce further injury have been studied and many others are underway. Neuroregenerative therapies are being extensively investigated, with cell based therapy being very promising.
\end{abstract}

Keywords: spinal cord injuries; spinal cord compression; neurosurgery; spinal cord regeneration; cell- and tissue-based therapy.

\section{RESUMO}

O traumatismo raquimedular (TRM) afeta 1.3 milhão de norte americanos, sendo mais da metade secundário a trauma.No Brasil, pouco estudos avaliaram sistematicamente a epidemiologia do TRM, mas estima-se uma incidência de 16 a 26 por milhão por ano. A extensão final do dano medular é resultante de mecanismos primários e secundários, que começam no momento do evento e prosseguem por dias e até semanas seguintes. Há fortes evidências de que a hipotensão contribua para danos secundários pós TRM. A cirurgia descompressiva visa a aliviar a compressão mecânica sobre a microcirculação, assim reduzindo isquemia e hipóxia. 0 papel da metilprednisolona no tratamento de pacientes com TRM é controverso, não sendo recomandada pela maior parte das diretrizes atuais. Terapias neuroprotetoras visando a reduzir injúria adicional foram e vêm sendo estudadas. Terapias neurorregenerativas estão sob investigação ampla, sendo a terapia celular uma forte promessa.

Palavras-chave: traumatismos da medula espinhal; compressão da medula espinal; neurocirurgia; regeneração da medula espinal; terapia baseada em transplante de células e tecidos.

Spinal cord injury (SCI) affects 1.3 million North Americans, with more than half occurring after trauma. In Brazil, few studies have evaluated the epidemiology of SCI with an estimated incidence of 16 to 26 per million per year. With the aging of the population, the incidence is expected to increase, mainly due to fall-related injuries. Direct lifetime costs can be as high as \$1.1-\$4.6 million per patient, and the consequences for the patients and their families can be devastating ${ }^{1,2}$.

\section{Search strategy}

A PubMed search for articles published up to September 2016 was performed using the terms "Spinal Cord Injury" [Mesh] and ("traumatic" [Title/Abstract]), which returned 4,346 articles. Additionally, the reference lists of the most recent guidelines on the management of spinal cord injury were searched. Two reviewers independently screened the article titles and abstracts. Articles with at least one abstract in English or Portuguese were searched.

\section{Pathophysiology}

The initial primary trauma causes mechanical injury to the spinal cord, a combination of compression, laceration, distraction or shearing. After the resulting damage to the microvasculature, progressive edema develops, ongoing ischemia worsens and a pro-apoptotic signaling is initiated. There is disruption of the blood-spinal cord barrier, influx of inflammatory cells, vasoactive peptides, and release of coagulation factors. These events promote thrombosis and spasm of the microvessels, leading to further hypoxia. An energetic crisis is installed, there is production of oxygen free radicals, and excitotoxicity and cytotoxic edema develop. With loss of the parenchymal volume, cystic cavities coalesce, generating a physical barrier to cell migration. Because of the distortion of the structural framework, regenerative attempts do not succeed. Proliferation of astrocytes and deposition of fibroblasts worsen the picture. The Rho-ROCK (rho-associated

1 Universidade Federal de São Paulo, Departamento de Neurologia e Neurocirurgia, São Paulo SP, Brasil.

Correspondence: Carolina Rouanet; Rua Pedro de Toledo, 650; 04039-002 São Paulo SP, Brasil; E-mail: carolrouanet@gmail.com

Conflict of interest: There is no conflict of interest to declare.

Received 11 January 2017; Accepted 14 March 2017. 
protein kinase) is activated and inhibits neurite outgrowth. Together, all those mechanisms contribute to the restriction of regeneration ${ }^{1,2}$.

The final extent of spinal cord damage results from primary and secondary mechanisms that start at the moment of the injury and go on for days and even weeks. Neuroprotective agents attempt to avert specific secondary injuries and prevent neural damage, while neuroregenerative therapies act to promote axonal regrowth after the damage has occured ${ }^{1}$.

\section{Neurological classification}

After initial general stabilization, it is important to perform a thorough neurological examination. The American Spinal Injury Association (ASIA) standard for neurological and functional classification is the recommended preferred tool. It is important as a means of standardizing the initial and follow-up examinations, and also has a role in predicting the prognosis ${ }^{3}$.

The tool consists of two components, the sensitive and the motor. The sensitive component comprises the testing of a key point in each of the 28 dermatomes (from C2 to S4-5) on the right and left sides. Light touch and pinprick sensation are also tested. Each modality is separately scored on a threepoint scale, ranging from 0 (absent) to 2 (normal or intact).

The motor examination encompasses testing of key muscle functions corresponding to ten paired myotomes (C5-T1 and L2-S1). Voluntary external anal sphincter contraction should also be tested. The strength should be graded according to the Medical Research Council grading system, from 0 to 5 .

With that, the neurological level of injury is determined as the most caudal segment of the cord with intact sensation and antigravity muscle function strength (Figure 1).

The ASIA Impairment Scale should be determined, as follows:

$\mathrm{A}=$ complete. No sensory or motor functions in sacral segments S4-S5.

$\mathrm{B}=$ sensory incomplete. Sensory but not motor function is preserved below the neurological level of injury including S4-S5 and no motor function is preserved more than three levels below the motor level on each side of the body.

$\mathrm{C}=$ motor complete. Motor function is preserved below the neurological level, and more than half the muscles below the neurological level of injury have a muscle grade less than 3.

$\mathrm{D}=$ motor incomplete. Motor function is preserved below the neurological level, and at least half the muscles below the neurological level of injury have a muscle grade $>3$.

$\mathrm{E}=$ Normal. Sensation and motor functions are normal in all segments tested ${ }^{4}$.

As previously mentioned, the ASIA Impairment Scale score has a prognostic value. Eighty-five percent of ASIA A patients will not regain function. Of the $15 \%$ who will improve, only $3 \%$ will have useful motor function. More than half (54\%) ASIA B patients, and the vast majority $(86 \%)$ of ASIA C-D patients will regain function ${ }^{5}$.

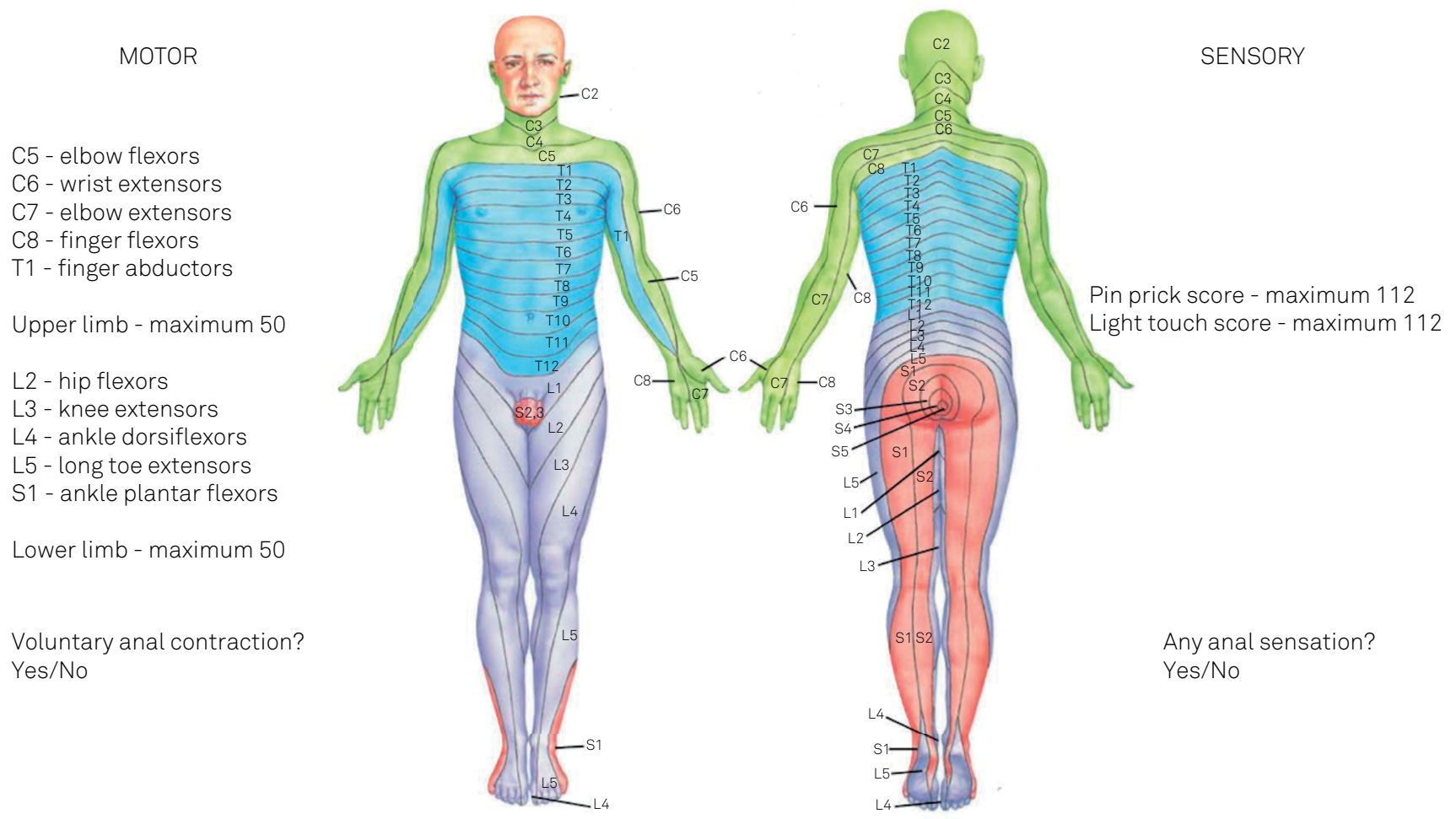

Figure. American Spinal Injury Association (ASIA) Standard Neurological classification of spinal cord injury. Steps of required motor and sensory examinations. 


\section{Imaging}

According to the last SCI guideline, trauma patients who have complaints of neck pain, spinal tenderness, symptoms or signs of a neurological deficit related to the spine, and patients who cannot be clearly assessed (the ones who are unconscious, uncooperative, incoherent or intoxicated) need a radiographic study of the spinal cord ${ }^{3}$.

The National Emergency X-Radiography Utilization Study (NEXUS) protocol was designed as an attempt to identify those at low risk for cervical fracture/subluxation/dislocation. It consists of five criteria: no posterior midline cervical tenderness, no intoxication, normal mental status, no other painful injuries and no neurological deficits. Patients meeting all of these criteria are at low risk of cervical injury and imaging of the neck or the spinal cord can be waived. The NEXUS protocol has a sensitivity of $99 \%$ and a negative predictive value of 99.9\% for cervical spinal cord injuries ${ }^{6}$.

Another protocol addressing the same issue is the Canadian C-Spine Rule, which consists of three questions: the presence of a high-risk factor that mandates radiography (age > 65 years, dangerous mechanism of trauma, or paresthesias in extremities), the presence of low risk factors allowing safe assessment of the range of motion, and the ability to actively rotate the neck $45^{\circ}$ to the left and right. The use of the Canadian C-Spine Rule protocol resulted in 100\% sensitivity for cervical spinal injury with a $42.5 \%$ specificity ${ }^{7}$.

The imaging modality of choice is computed tomography (CT). If it is not available, a three-view spine $\mathrm{x}$-ray is recommended (anteroposterior, odontoid and lateral views), being supplemented later by a CT scan ${ }^{3}$.

Magnetic resonance imaging should be obtained, when feasible, in the first 48 hours after the trauma. It can detect lesions in $6 \%$ of the cases in which the CT is normal, and is particularly useful for ligamentous lesions. It is also a valuable tool to classify severity and predict outcome based on the presence of hemorrhage, extent of edema, and severity of the initial compression. Intraspinal hemorrhages ( $>1 \mathrm{~cm}$ long) as well as longitudinal T2 signal changes $>3 \mathrm{~cm}$, are associated with poor prognosis. A normal initial magnetic resonance image is usually associated with complete recovery8.

\section{Airway management}

Respiratory complications are the main cause of morbidity and mortality in the acute phase of the SCI, with incidence ranging from $36 \%$ to $83 \%$. Reduced vital capacity, retention of secretions, and autonomic dysfunction all play a role. Up to two thirds of patients will have complications such as atelectasis, pneumonia, or respiratory failure that require mechanical ventilation'.

The injury level and the ASIA classification are the two most important predictors for the need of intubation. Virtually $100 \%$ of lesions above C5 require intubation (the phrenic nerve originates from C3-C5), which should be performed electively rather than as an emergency. It is important to avoid hyperextension, rotation, and other movements of the neck during intubation. When possible, awake, fiberoptic intubation is preferred. In-line stabilization without traction is an alternative when a fiber optic laryngoscope or bronchoscope is unavailable?

In selected patients with complete cervical lesions or in those with incomplete or lower lesions, conservative management might be an option. In such cases, lung function should be monitored closely with vital capacity, maximum inspiratory pressure and carbon dioxide partial pressure levels. Those measures can predict the need for intubation?.

With regard to ventilator weaning, only $40 \%$ of patients with lesions above $\mathrm{C} 4$ are successfully extubated. Predictors of the need for tracheostomy are ASIA A lesions, extent of the lesion, smoking, and previous lung disease. Some studies advocate that early tracheostomy (within 10 days) in these patients leads to a shorter ICU stay and reduction in the length of time of mechanical ventilation ${ }^{10}$.

\section{Cardiovascular management}

Hypotension after SCI is frequent. It may be due to hypovolemia in a context of polytrauma, or due to the direct cervical or thoracic spinal trauma itself, leading to neurogenic shock. Neurogenic shock results from the interruption of sympathetic tone due to disruption in supraspinal control, and an intact parasympathetic influence via the vagus nerve, leading to an imbalance in the autonomic control. There is, therefore, loss of peripheral vascular tone and bradycardia ${ }^{11}$.

Although the deleterious consequences of hypotension in SCI have not been assessed in a controlled prospective way, there is convincing evidence that hypotension contributes to secondary injury after acute SCI, reducing spinal cord flow and perfusion. Based on this, the current recommendation is to strictly avoid hypotension, and maintain mean arterial pressure (MAP) at $85-90 \mathrm{mmHg}$ for seven days after injury (level III evidence) $)^{3}$. In order to achieve that goal, the mainstay of treatment is intravenous fluid therapy (mainly with crystalloids) to maintain a euvolemic or slightly hypervolemic status, in association with vasopressors ${ }^{2}$. It is important to have invasive blood pressure monitoring with an arterial line.

The main predictors of poor cardiovascular function requiring resuscitation and support are high cervical and complete lesions ${ }^{12}$. Cardiovascular instability may be transient and episodic, but can also be recurrent in the first 7-10 days after injury.

The best vasoactive amine is still a matter of debate. The last guideline does not address this controversy. A systematic review tried to answer several questions regarding the use of vasopressors in acute SCI. However, it was inconclusive in determining which vasopressor is better, what the optimal therapy duration is and what the MAP level is below which one should initiate vasopressor support ${ }^{13}$.

The vasopressor selection may depend on the level of the SCI and on the patient's hemodynamics. In cervical or high 
thoracic lesions with both hypotension and bradycardia, a drug with chronotropic and inotropic effects as well as vasoconstrictor properties might be required. Norepinephrine (or alternatively, dopamine) could be good options. For low thoracic lesions, where hypotension is usually the result of peripheral vasodilation, a pure vasopressor drug such as phenylephrine could be appropriate ${ }^{14}$.

Recently, some studies have addressed the frequency of side effects and rates of complications related to the use of vasoactive drugs in this population. A high rate of cardiogenic complications was found, with up to $70 \%$ of patients experiencing at least one of the following: tachycardia, bradycardia, elevated troponin, new onset atrial fibrillation, atrial flutter, or eletrocardiogram ST changes consistent with ischemia. A higher rate of side effects with the use of dopamine compared to norepinephrine and phenylephrine was described, especially in the population older than 55-60 years ${ }^{15,16,17}$.

Recently, Altaf and collaborators compared the effects of norepinephrine versus dopamine on MAP, the intrathecal pressure (monitored with a lumbar intrathecal catheter) and spinal cord pressure perfusion (the difference between MAP and intrathecal pressure). The conclusion was that norepinephrine was able to maintain MAP with a lower intrathecal pressure and correspondingly higher spinal cord pressure perfusion ${ }^{18}$.

These findings have led to a non-inferiority trial design called the "Mean Arterial Blood Pressure Treatment for Acute Spinal Cord Injury", comparing the avoidance of hypotension (MAP $\geq 65 \mathrm{mmHg}$ ) versus the induction of hypertension (MAP $\geq 85 \mathrm{mmHg}$ ), which is currently recruiting patients and is expected to be completed in $2017^{19}$.

\section{Decompressive Surgery}

Progressive edema and hemorrhage contribute to the ongoing mechanical pressure on the microvascular circulation. Surgical decompression aims to relieve this pressure, thereby reducing secondary hypoxia and ischemia ${ }^{2}$.

Indications for surgery include significant cord compression with progressive neurological impairment and a fracture not amenable to, or not responding to, close reduction, such as unstable vertebral fractures.

The Surgical Timing in Acute Spinal Cord Injury Study was a prospective, observational study that compared patients who had undergone surgery before and after 24 hours from injury. The first group was more than twice as likely to have a two grade ASIA Impairment Scale improvement and a similar complication rate compared to the group with late surgery ${ }^{20}$.

Those findings were confirmed in a prospective Canadian cohort study even after adjusting for preoperative status and neurological level ${ }^{21}$.

With that, the concept of "time is spine" has emerged, and the ongoing recommendation is surgical decompression in the first 24 hours $^{3}$.
The SCI-POEM is a European multicenter study that is currently recruiting patients with the aim to compare decompression < 12hours versus > 12 hours until 14 days. The final report is planned to be published in the end of $2017^{22}$.

\section{Intravenous methylprednisolone}

Methyprednisolone (MP) is a synthetic corticosteroid that upregulates anti-inflammatory factors and decreases oxidative stress, enhancing endogenous cell survival in animal models of SCI. It reduces edema, prevents intracellular potassium depletion and inhibits lipid peroxidation ${ }^{1}$.

Since the 1980s, clinical trials have been trying to demonstrate its benefits in humans. The National Spinal Cord Injury Study I, published in 1984, examined 1000mg bolus MP followed by the same dose daily for 10 days, compared to $100 \mathrm{mg}$ bolus and then daily. No difference in motor or sensitive neurological recovery was observed between groups, and wound infections were more prevalent in the high-dose group ${ }^{23}$.

The National Spinal Cord Injury Study II, published in 1990, compared MP 30mg/kg intravenously followed by $5.4 \mathrm{mg} / \mathrm{kg} / \mathrm{h}$ over 23 hours to naloxone and placebo. At one year, there was no significant difference in neurological function among the groups. A subanalysis found that the subset of patients who received the corticosteroid within eight hours had a modest improvement in motor recovery. Wound infections were more frequent among MP patients ${ }^{24}$.

The National Spinal Cord Injury Study III, published in 1997, compared three treatment groups: MP for 48 hours, the same drug administered for 24 hours and tirilazad mesylate (a potent lipid peroxidation inhibitor). Patients were treated within eight hours of SCI. In a post hoc analysis, in patients treated between three to eight hours from trauma, the 48-hour regimen was associated with a greater motor, but not functional, recovery. In addition, the group with the longer duration had more severe sepsis and pneumonia ${ }^{25}$.

Recently, a meta-analysis and systematic review concluded that evidence from multiple randomized controlled trials and also from observational studies do not support methylprednisolone use in acute SCI since it has no long-term benefits. Besides, it increases gastrointestinal hemorrhage and has a trend to increase overall adverse events ${ }^{26}$.

The last consensus does not recommend MP for treatment of $\mathrm{SCI}^{3}$.

\section{Neuroprotection}

Neuroprotective agents aiming to reduce secondary insults are potential key therapies in SCI. Multiple approaches have been studied, and many others are currently under investigation.

Gangliosides are glycolipid molecules present in neuronal membranes. Laboratory studies have shown that they can enhance axonal regeneration, besides having a variety of neuroprotective effects, such as prevention of apoptosis and anti-excitotoxic activity. GM-1 (Sygen) was suggested as a therapeutic option until the 2002 guideline (although without 
demonstrated clinical benefit) ${ }^{27}$. However, a randomized controlled trial of the ganglioside compound reported no difference in neurological recovery after six months, therefore, it is no longer recommended ${ }^{3,28}$.

Naloxone, an opioid antagonist, was tested in the National Spinal Cord Injury Study II trial together with MP and placebo. The study was negative, with no differences in motor scores between groups ${ }^{24}$.

Nimodipine is an L-type calcium channel blocker thought to prevent calcium- dependent apoptotic enzymes and block presynaptic release of glutamate. In comparison with placebo, however, no difference in neurological status at one year was noted ${ }^{29}$.

Tirilazad mesylate, a drug that attenuates peroxidation of neuronal membranes, was analyzed together with MP in the National Spinal Cord Injury Study III trial, with no difference between groups. There are no placebo-controlled studies ${ }^{25}$.

In animal studies, hypothermia decreased basal metabolic rate in the central nervous system, reduced inflammation, apoptosis, excitotoxicity, edema, gliosis, and increased angiogenesis. As well, traumatic SCI models showed improvement with the decreased temperature ${ }^{30}$. A small pilot study in humans with SCI exposed to hypothermia showed a trend towards neurological recovery (43\% vs 21\%) and no difference in complication rates ${ }^{31}$. Another study evaluated 35 ASIA A patients who were treated with hypothermia $\left(33^{\circ} \mathrm{C}\right)$ for 48 hours, starting in the first six hours post-injury. Four patients converted to ASIA B in the first 24 hours. In the remaining patients, $35.5 \%$ showed an improvement of at least one grade on the ASIA scale at the latest follow-up ${ }^{32}$.

These promising results led to a phase II/III trial named "The Acute Rapid Cooling Therapy for Injuries of the Spinal Cord". This study (which is not yet recruiting) plans to evaluate different durations of hypothermia, starting within six hours post-trauma.

Riluzole, a sodium-channel blocker, reduces secondary injury by blocking pathological activation of sodium channels and reducing the release of glutamate in preclinical models of SCI. A phase I/II trial demonstrated a benefit in motor scores in patients treated with the drug ${ }^{33}$. A phase II/III trial, the Riluzole in Spinal Cord Injury Study, is ongoing, to evaluate the aforementioned drug in cervical lesions. It will be completed in $2018^{34}$.

Minocycline is an antibiotic with anti-inflammatory properties including inhibition of tumor necrosis factor alpha, interleukin 1 beta, cyclooxygenase- 2 and nitric oxide synthase. In pre-clinical models, it decreased lesions sizes and neuron loss. In a phase II study, the ASIA motor score improved in patients treated with minocycline $(p=0.05)^{35}$. This led to a phase III trial, the Minocycline in Acute Spinal Cord Injury, which is currently recruiting patients until $2018^{36}$.
Fibroblast growth factor has been shown to protect against excitotoxicity and to reduce free radical production in animal models of SCI. A fibroblast growth factor analogue called SUN 13837 was evaluated in a phase I/II trial completed in 2015, but results are still pending ${ }^{37}$.

Cytokine granulocyte colony stimulating factor is neuroprotective in SCI by promoting cell survival and inhibiting tumor necrosis factor alpha and interleukin 1 beta. There were two small, non-randomized studies that demonstrated improvements in ASIA motor scores with the drug use $\mathrm{s}^{38,39}$.

\section{Neuroregeneration}

A wide number of strategies are being developed worldwide to help recovery in SCI patients. There are numerous targets and therapeutic opportunities using endogenous and exogenous repair mechanisms. The aim is to surpass barriers to recovery such as the loss of structural framework, cystic cavitation, scarring and inhibitory molecular signaling ${ }^{2}$.

Cell-based therapies are promising modalities of regeneration. A wide number of cell types have been studied or are being evaluated in ongoing studies - embryonic stem cells, induced pluripotent stem cells, olfactory ensheathing cells, Schwann cells, mesenchymal cells, and activated autologous macrophages. In preclinical studies, cellular transplantation alone, or in combination with other therapies, was associated with neurological recovery, without any subtype showing superiority over the other. Small human studies also disclosed some degree of improvement, with no major adverse events. However, it is important to notice that, independent of treatment, most patients will undergo some spontaneous recovery in the first six months after injury. Therefore, confounding factors cannot be excluded from these results ${ }^{1}$.

Embryonic and induced pluripotent stem cells are capable of remyelinate axons, modulate the inflammatory response, regenerate lost neural circuits and modify the microenvironment. Schwann cells are able to remyelinate central nervous system axons and, in animal models, have reduced cystic cavitation, enhanced tissue sparing and enhanced recovery. Olfactory ensheathing cells are phagocytes capable of clearing microbes and debris and also of secreting neurotropic factors. In animals, they enhanced axonal regeneration and remyelination and also improved outcomes. Mesenchymal cells can differentiate along their connective tissue lineages and modulate inflammatory response at systemic and local environment levels. They have been shown to decrease inflammatory cell infiltration, increase pro-survival trophic factor levels and promote tissue sparing ${ }^{1,2}$.

It should be noted that cellular transplantation remains an investigational and experimental therapy, with no formal recommendations. 


\section{FINAL REMARKS}

Spinal cord injury management has substantially changed over the last years. Key early interventions are increasingly being recognized, as well as the need to better study these patients. Neuroprotective and neuroregenerative strategies are probably more effective when done together, and they are an extensive field of current and future research. The pending trial results can have a significant impact on the standard of care, given that even small motor or sensory improvements can have profound effects on patients' lives.

\section{References}

1. Wilson JR, Forgione N, Fehlings MG. Emerging therapies for acute traumatic spinal cord injury. CMAJ. 2013;185(6):485-92. https://doi.org/10.1503/cmaj.121206

2. Ahuja CS, Martin AR, Fehlings MG. Recent advances in managing spinal cord injury secondary to trauma. F1000 Research. 2016;5(F1000 Faculty Rev):1017. https://doi.org/1010.12688/f1000 research.7586.1

3. Resnick DK. Update guidelines for the management of acute cervical spine and spinal cord injury. Neurosurgery. 2013;72( suppl 3):1.. https://doi.org/10.1227/NEU.0b013e318276ee7e

4. Kirshblum SC, Burns SP, Biering-Sorensen F, Donovan W, Graves DE, Jha A et al. International standards for neurological classification of spinal cord injury (revised 2011).J Spinal Cord Med. 2011;34(6):535-46. https://doi.org/10.1179/204577211X13207446293695

5. Le CT, Price M. Survival from spinal cord injury. J Chronic Dis. 1982;35(6):487-92. https://doi.org/10.1016/0021-9681(82)90063-7

6. Hoffman JR, Mower WR, Wolfson AB, Todd KH, Zucker MI. Validity of a set of clinical criteria to rule out injury to the cervical spine in patients with blunt trauma. N Engl J Med. 2000;343(2):94-9. https://doi.org/10.1056/NEJM200007133430203

7. Stiell IG, Wells GA, Vandemheen KL, Clement CM, Lesiuk H, De Maio VJ et al. The Canadian C-spine rule for radiography in alert and stable trauma patients. JAMA. 2001;286(15):1841-8. https://doi.org/10.1001/jama.286.15.1841

8. Krishna V, Andrews H, Varma A, Mintzer J, Kindy MS, Guest J. Spinal cord injury: how can we improve the classification and quantification of its severity and prognosis? J Neurotrauma. 2014;31(3):215-27. https://doi.org/10.1089/neu.2013.2982

9. Vazquez RG, Sedes PR, Farina MM, Marques AM, Velasco EF. Respiratory management in the patient with spinal cord injury. BioMed Res Int. 2013;2013:168757. http://dx.doi.org/10.1155/2013/168757

10. Choi HJ, Paeng SH, Kim ST, Lee KS, Kim MS, Jung YT. The effectiveness of early tracheostomy in cervical spinal cord injury patients.J Korean Neurosurg Soc. 2013;54:220-4. https://doi.org/10.3340/jkns.2013.54.3.220

11. Hagen, EM. Acute complications of spinal cord injuries. World $J$ Orthop. 2015;6(1):17-23. https://doi.org/10.5312/wjo.v6.i1.17

12. Casha S, Christie S. A systematic review of intensive cardiopulmonary management after spinal cord injury. J Neurotrauma. 2011;28(8):1479-95. https://doi.org/10.1089/neu.2009.1156

13. Ploumis A, Yadlapalli N, Fehlings MG, Kwon BK, Vaccaro AR. A systematic review of the evidence supporting a role for vasopressor support in acute SCI. Spinal Cord. 2010;48(5):356-62. https://doi.org/10.1038/sc.2009.150

14. Consortium for Spinal Cord Medicine. Early acute management in adults with spinal cord injury: a clinical practice guideline for health-care professionals. J Spinal Cord Med. 2008;31(4):403-79. https://doi.org/10.1080/10790268.2008.11760744

15. Readdy WJ, Whetstone WD, Ferguson AR, Talbott JF, Inoue T, Saigal R. Complications and outcomes of vasopressor usage in acute traumatic central cord syndrome. J Neurosurg Spine. 2015;23(5):574-80. https://doi.org/10.3171/2015.2.SPINE14746
16. Readdy WJ, Dhall SS. Vasopressor administration in spinal cord injury: should we apply a universal standard to all injury patterns? Neural Regen Res. 2016;11(3):420-1. https://doi.org/10.4103/1673-5374.179051

17. Inoue T, Manley GT, Patel N, Whetstone WD. Medical and surgical management after spinal cord injury: vasopressor usage, early surgeries and complications. J Neurotrauma. 2014;31(3):284-91. https://doi.org/10.1089/neu.2013.3061

18. Altaf F, Griesdale DE, Belanger L, Ritchie L, Markez J, Ailon T et al. The differential effects of norepinephrine and dopamine on cerebrospinal fluid pressure and spinal cord perfusion pressure after acute human spinal cord injury. Spinal Cord. 2017;55(1):33-8. https://doi.org/10.1038/sc.2016.79

19. Jacobs WB. Mean arterial blood pressure treatment for acute spinal cord injury (MAPS). Clinical Trials.gov. NCT 02232165. 2016 [cited 2016 Aug 16]. Available from: https://clinicaltrials.gov/ ct2/show/NCT02232165?term =NCT+02232165\&rank=1

20. Fehlings MG, Vaccaro A, Wilson JR, Singh A, W Cadotte D, Harrop JS et al. Early versus delayed decompression for traumatic cervical spinal cord injury: results of the Surgical Timing in Acute Spinal Cord Injury Study (STASCIS). PLoS One. 2012;7(1):e32037. https://doi.org/10.1371/journal.pone.0032037

21. Wilson JR, Singh A, Craven C, Verrier MC, Drew B, Ahn H et al. Early versus late surgery for traumatic spinal cord injury: the results of a prospective Canadian cohort study. Spinal Cord. 2012;50(11):840-3. https://doi.org/10.1038/sc.2012.59

22. AOSpine Europe. Surgical treatment for spinal cord injury (SCI-POEM). Clinical Trials.gov. NCT 01674764. 2012 [cited 2016 Sep 13]. Available from: https://clinicaltrials.gov/ct2/show/NCT01674764 ?term $=$ NCT $+01674764 \&$ rank $=1$

23. Bracken MB, Collins WF, Freeman DF, Shepard MJ, Wagner FW, Silten RM et al. Efficacy of methylprednisolone in acute spinal cord injury. JAMA. 1984;251(1):45-52. https://doi.org/10.1001/jama.1984.03340250025015

24. Bracken MB, Shepard MJ, Collins WF, Holford TR, Young W, Baskin DS et al. A randomized, controlled trial of methylprednisolone or naloxone in the treatment of acute spinal cord injury: results of the Second National Acute Spinal Cord Injury Study. N Engl J Med. 1990;322(20):1405-11. https://doi.org/10.1056/NEJM199005173222001

25. Bracken MB, Shepard MJ, Holford TR, Leo-Summers L, Aldrich EF, Fazl $\mathrm{M}$ et al. Administration of methylprednisolone for 24 or 48 hours or tirilazad mesylate for 48 hours in the treatment of acute spinal cord injury: results of the Third National Acute Spinal Cord Injury Randomized Controlled Trial. JAMA. 1997;277(20):1597-604. https://doi.org/10.1001/jama.1997.03540440031029

26. Evaniew N, Belley-Côté EP, Fallah N, Noonan VK, Rivers CS, Dvorak MF. Methylprednisolone for the treatment of patients with acute spinal cord injuries: a systematic review and meta-analysis. J Neurotrauma. 2016;33(5):468-81. https://doi.org/10.1089/neu.2015.4192

27. Hadley MN, Walters BC, Grabb PA, Oyesiku NM, Przybylski GJ, Resnick DK, Ryken TC. Guidelines for the management of acute cervical spine and spinal cord injuries. Neurosurgery. 2002;50(2 Suppl):S1. 
28. Geisler FH, Coleman WP, Grieco G, Poonian D. The Sygen multicenter acute spinal cord injury study. Spine. 2001;26(24 Suppl):87-98. https://doi.org/10.1097/00007632-200112151-00015aa

29. Petitjean ME, Pointillart V, Dixmerias F, Wiart L, Sztark F, Lassié $P$ et al. [Medical treatment of spinal cord injury in the acute stage]. Ann Fr Anesth Reanim. 1998;17(2):115-22. French. https://doi.org/10.1016/S0750-7658(98)80058-0

30. Wang J, Pearse DD. Therapeutic hypothermia in spinal cord injury: the status of its use and open questions. Int J Mol Sci. 2015;16(8):16848-79. https://doi.org/10.3390/ijms160816848

31. Levi AD, Green BA, Wang MY, Dietrich WD, Brindle T, Vanni S et al. Clinical application of modest hypothermia after spinal cord injury.J Neurotrauma. 2009;26(3):407-15. https://doi.org/10.1089/neu.2008.0745

32. Dididze M, Green BA, Dietrich WD, Vanni S, Wang MY, Levi AD. Systemic hypothermia in acute cervical spinal cord injury: a case-controlled study. Spinal Cord. 2013;51(5):395-400. https://doi.org/10.1038/sc.2012.161

33. Grossman RG, Fehlings MG, Frankowski RF, Burau KD, Chow DS, Tator $\mathrm{C}$ et al. A prospective, multicenter, phase I matched-comparison group trial of safety, pharmacokinetics, and preliminary efficacy of riluzole in patients with traumatic spinal cord injury. J Neurotrauma. 2014;31(3):239-55. https://doi.org/10.1089/neu.2013.2969

34. AOSpine North America Research Network. Riluzole in spinal cord injury study. (RISCIS). 2016 [cited 2016 Jul 13]. Clinical Trials.gov.
NCT 01597518. Available from: https://clinicaltrials.gov/ct2/show/ NCT01597518?term =NCT+01597518\&rank=1

35. Casha S, Zygun D, McGowan MD, Bains I, Yong VW, Hurlbert RJ. Results of phase II placebo-controlled randomized trial of minocycline in acute spinal cord injury. Brain. 2012;135(4):1224-36. https://doi.org/10.1093/brain/aws072

36. Rick Hansen Institute. Minocycline in acute spinal cord injury (MASC). Clinical Trials.gov. NCT 01828203. 2014 [cited 2014 Oct 16]. Available from: https://clinicaltrials.gov/ct2/show/NCT01828203?ter $\mathrm{m}=\mathrm{NCT}+01828203 \& \mathrm{rank}=1$

37. Daiichi Sankyo Inc. Study to evaluate the efficacy, safety, and pharmacokinetics of SUN13837 injection in adult subjects with Acute Spinal Cord Injury (ASCI). Clinical Trials.gov. NCT01502631. 2016 [cited 2016 Aug 11]. Available from: https://clinicaltrials.gov/ ct2/show/NCT01502631?term =NCT01502631\&rank=1

38. Kamiya K, Koda M, Furuya T, Kato K, Takahashi H, Sakuma T et al. Neuroprotective therapy with granulocyte colony-stimulating factor in acute spinal cord injury: a comparison with high-dose with methylprednisolone as a hystorical control. Eur Spine J. 2015;24(5):963-7. https://doi.org/10.1007/s00586-014-3373-0

39. Takahashi H, Yamazaki M, Okawa A, Sakuma T, Kato K, Hashimoto $\mathrm{M}$ et al. Neuroprotective therapy using granulocyte colony-stimulating factor for acute spinal cord injury: a phase I/Ila clinical trial. Eur Spine J. 2012;21(12):2580-7. https://doi.org/10.1007/s00586-012-2213-3 